\title{
Com quantos nós se faz uma trama: ressonâncias do teatro do oprimido em A corda, de Pepetela
}

\author{
How many knots make a plot: \\ resonances of the theater of the oppressed in \\ A corda, by Pepetela
}

\begin{abstract}
JoRge Vicente VALENTim*
RESUMO: ESCRITA EM 1976, OU SEJA, POSTERIORMENTE AOS ROMANCES MUANA PUÓ (1969), MAYOMBE (1971) E AS AVENTURAS DE NGUNGA (1972), A PEÇA A CORDA, DE PEPETELA, TRAZ JÁ NO SEU BOJO MARCAS DISTINTIVAS DO PROJETO LITERÁRIO DO SEU AUTOR. PASSANDO DA FICÇÃO ROMANESCA PARA A DRAMÁTICA, PEPETELA APOSTA NUM TEATRO REFLEXIVO, ESTABELECENDO UM DIÁLOGO TANTO COM AS IDEIAS DE BRECHT, QUANTO COM AS DO TEATRO DO OPRIMIDO, DE AUGUSTO BOAL.

ABSTRACT: WRITTEN IN 1976, SUBSEQUENT TO HIS NOVELS MUANA PUÓ (1969), MAYOMBE (1971) AND AS AVENTURAS DE NGUNGA (1972), PEPETELA'S PLAY A CORDA BRINGS HALLMARKS OF THE LITERARY PROJECT OF ITS AUTHOR. MOVING FROM ROMANTIC FICTION TO THE DRAMATIC, PEPETELA BETS IN A REFLEXIVE THEATER, ESTABLISHING A DIALOGUE WITH BOTH THE IDEAS OF BRECHT, AND WITH THE THEATRE OF THE OPPRESSED, BY AUGUSTO BOAL.
\end{abstract}

PALAVRAS-CHAVE: TEATRO DO OPRIMIDO; LITERATURA E POLÍTICA; AUGUSTO BOAL E PEPETELA. KEYWORDS: THEATRE OF THE OPPRESSED; LITERATURE AND POLITICS; AUGUSTO BOAL AND PEPETELA.

* Universidade Federal de São Carlos, São Carlos, São Paulo, Brasil. E-mail: jvvalentim@gmail.com. 


\section{o teatro africano ao teatro de Pepetela}

A capacidade do teatro apelar à consciência do Povo - mostrando-lhe os mecanismos da própria alienação e os obstáculos à sua libertação - confere-lhe o caráter de enorme força mobilizadora e transformadora. A sua aç̧ão é indireta. O teatro não transforma directamente o mundo, mas pode exercer um profundo efeito sobre a consciência dos que o vão transformar.

(José Mena Abrantes. O teatro em Angola)

Muito pouco se fala ou se produz sobre o teatro na África. Dentro dos estudos críticos das literaturas africanas de língua portuguesa, alguns raros se aventuram em abordagens e leituras de textos dramáticos produzidos por escritores dos seus diferentes sistemas literários.

Num primeiro momento, tal questão poderia ser colocada em razão da pequena produtividade deste gênero, em relação a outros como a ficção e a poesia. Ainda assim, a par de uma visível porcentagem menor, tal argumento não parece ser suficiente para sustentar este quase silenciamento, gerando uma espécie de inquietação àqueles que sobre o tema se debruçam, ainda mais se levada em conta a expressividade de certos títulos, como $A$ corda $(1978)^{1}$ e $A$ revolta da casa dos ídolos (1980), de Pepetela; No velho ninguém toca (1979), de Costa Andrade; Diálogo com a peripécia (1987) e As colbeiras do senhor governador (2010), de João Maimona; As mortes de Lucas Mateus, de Leite de Vasconcelos (2000); Capitango (1998) e O rei do Obó (1999), de Fernando de Macedo; Apocalypse Now (2004), de Arménio Vieira; apenas para citar alguns dos mais reconhecidos autores, sem incluir nesta lista um elenco considerável de outros escritores com obras adaptadas para a dramaturgia ${ }^{2}$.

Com este elenco, começo a interrogar se, realmente, inexiste uma produtividade textual dramática nos PALOP, como certas informações veiculadas no universo internético nos fazem $\mathrm{crer}^{3}$. Ainda que de forma incipiente, é

1. As datas referem-se à primeira edição das obras citadas.

2. Dentre estes, podemos citar As virgens loucas, de António Aurélio Gonçalves (1996, adaptação de Cândido Ferreira); Os dois irmãos, de Germano Almeida (1999, adaptação de Francisco Cruz) e Mar me quer, de Mia Couto (2001, adaptação de Natália Luíza).

3. É lamentável que, ainda hoje, encontremos declarações como esta: "O texto dramático ainda não foi explorado pelos autores moçambicanos, o que significa que não existem autores de teatro em Moçambique." (sic!), em sites procurados como a wikipedia <http://pt.wikipedia.org/wiki/Literatura_de_Mo\% $\% 3 \%$ A 7 ambique>. 
possível detectar algumas vozes críticas dedicadas às manifestações do gênero nas mais distintas literaturas africanas. Desde longos estudos dedicados a um autor (ALMEIDA, 1978; HILDEBRANDO, 1996), passando por leituras centradas em diferentes sistemas literários (ABRANTES, 2004; BRANCO, 2003 e 2004; CAETANO, 2004; VAZ, 1999), até recensões críticas e ensaios esparsos em periódicos e coletâneas sobre algumas obras de escritores específicos, entre eles, o próprio Pepetela (AMÂNCIO, 2009; DESTI, 1980; CARNEIRO, 1982; HILDEBRANDO, 2009; REBELLO, 1981), já se pode ponderar que não se trata, na verdade, de uma inexistência de produção dramática, mas, talvez, de uma falta de interesse, por motivos das mais diversas ordens, na pesquisa e na leitura deste acervo.

O propósito aqui adotado, portanto, é o de contribuir para os estudos sobre a produção teatral na literatura angolana, verificando como certos recursos dramáticos utilizados por Pepetela, na construção de sua peça de estréia no gênero, A corda, escrita em 1976 e publicada em 1978, dialogam com práticas estéticas comuns à sua época, dentre elas, as do teatro do oprimido, de Augusto Boal.

Sem querer problematizar a questão, se existe (ou não) um teatro designado como "teatro africano", como faz José Mena Abrantes (2004), assumo, desde já, a responsabilidade pelo termo, a que o próprio crítico e dramaturgo angolano lança mão, qual seja, refiro-me a um teatro de autoria africana, "feito por africanos para africanos tratando de temas africanos" (ABRANTES, 2004, p. 49), ainda que os seus resultados finais não sejam aqueles esperados pelo eminente crítico.

Neste sentido, gosto de pensar que o teatro de Pepetela não só preenche as lacunas do epíteto (trata-se de um texto de autoria africana, destinado a um público africano e sobre um quadro político-social específico de Angola), mas também confirma e consolida a presença do gênero no continente e na literatura angolana, sem perder de vista as tendências criadoras em voga na época de sua escrita. Por este viés, fica claro, portanto, que a proposta deste ensaio é a leitura do texto dramático em si, e não dos espetáculos ou das encenações realizadas do mesmo. E, ainda que, em alguns momentos, os recursos contidos nas rubricas sejam levados em consideração, é a obra pepeteliana que aqui nos interessa e os desdobramentos de sua mensagem discursiva.

Como tal, acreditamos que o teatro de Pepetela exerce sobremaneira aquela função esclarecedora e pedagógica, suscitada por José Mena Abrantes 
(2004), sem, no entanto, abrir mão de chamar para as malhas do texto tanto as ressonâncias brechtianas de um teatro altamente reflexivo e interrogador, quanto os vestígios de recursos dramáticos, típicos de um teatro do oprimido, defendido e praticado pelo brasileiro Augusto Boal. Deste modo, a aposta de Pepetela parece residir num teatro com "força mobilizadora e transformadora" (ABRANTES, 2004, p. 24), expondo as vicissitudes sociais de um cenário angolano pós-1975 e chamando a atenção para um posicionamento dos seus leitores/espectadores, com uma sensibilidade singular capaz de reunir a reflexão ativa e a atitude reagente diante do quadro encenado. Consegue seu autor, neste sentido, estabelecer um diálogo com uma certa práxis muito cara à dramaturgia brasileira no contexto da década de 1970, vislumbrando nos conjuntos de personagens e na situação performatizada, para além de um gesto artístico e criador, uma bem-sucedida aventura estética de "ordenar a realidade, torná-la cognoscível, inteligível, perceptível nas suas razões mais profundas, e não apenas na sua aparência” (BOAL, 1980a, p. 20). ${ }^{4}$

\section{Oprimidos e revolucionários: nós d' A corda de Pepetela}

Na medida em que o perigo para a África actual é o de não se ver senão com os olhos dos outros, convém sem dúvida que o teatro dê ocasião de pôr publicamente os problemas que a atormentam e que ele seja para o povo não só fonte de cultura nacional mas também pedagogia para a tomada de consciência.

(Carlos Vaz. Para um conbecimento do teatro africano.)

4. Ainda que seja necessária uma verificação mais centrada nos elementos extratextuais motivadores da escrita desta peça de Pepetela - inclusive se existe algum tipo de diálogo ou mesmo uma correspondência entre o autor angolano e o dramaturgo brasileiro -, não podemos nos furtar a estabelecer uma ligação duplamente frutífera neste projeto dramático pepeteliano. Em primeiro lugar, com certos pressupostos brechtianos, levando em conta, sobretudo, a grande contribuição para os estudos críticos da tradução da obra Estudos sobre teatro: para uma arte dramática não-aristotélica, realizada pela escritora portuguesa Fiama Hasse Pais Brandão, em 1964, e publicada pela Portugália Editora. Em segundo lugar, com as propostas de Augusto Boal, contidas em sua "Poética do oprimido", escrita em 1973, e no seu "Sistema 'coringa", criado em 1967, ambos publicados na 1'. edição de seu Teatro do oprimido, em 1975. Como dissemos, ainda que não haja registro escrito da confissão do autor d' A corda com tais tendências, a proximidade de datas das publicações e das divulgações de ideias nos leva a pensar num diálogo possível entre os dramaturgos alemão e brasileiro e o escritor angolano. 
Centrada em dois grupos que encenam uma disputa de cabo de guerra (o dos imperialistas e o dos revolucionários), a peça de Pepetela traz no seu bojo o jogo antagônico de forças com interesses vários e distintos, cujo prêmio para o vencedor é a própria nação angolana, subentendendo-se aí o seu território e as suas riquezas naturais.

Mediado por Likishi, uma espécie de juiz que tenta, a princípio, manter uma neutralidade diante da disputa, os dois conjuntos são formados por personagens bem marcados, funcionando em alguns momentos como uma espécie de representação alegórica de correntes político-ideológicas presentes no cenário social angolano. Tal divisão pode ser percebida na própria distribuição inicial do texto, quando os atores indicados para a performance "devem ser, de preferência, crianças dos 12 aos 19 anos" (PEPETELA, 1978, p. 7).

Aqui, é preciso perceber também uma nítida inclinação pedagógica - como aquela presente na criação de $A$ s aventuras de Ngunga, por exemplo ${ }^{5}$-, no sentido de que os pequenos atores envolvidos na ação podem representar uma necessidade educativa de esclarecimento ideológico. Interessa, portanto, ao seu autor, não apenas sensibilizar as futuras gerações para uma atividade artística, mas, também, e sobretudo, para uma consciência política no país. Mas, para além disto, se o grupo de atores apresenta um aspecto homogeneizador na sua faixa etária, na performance dos papéis, há uma nítida diferença entre eles.

O primeiro grupo compõe-se de personagens nomeados a partir de figuras históricas e pertencentes a um momento histórico recente em Angola, e levando igualmente consigo a identificação de povos interessados na exploração das riquezas locais, sem esconder em momento algum as suas ambições. Fazem parte deste conjunto o americano imperialista, "branco, de preferência gordo, sorridente, com um chapéu de estrelas brancas sobre fundo azul" (Ibidem); Holden, líder da FNLA (Frente Nacional de Libertação de Angola), caracterizado com seus "eternos óculos escuros, um barrete de pele de leopardo" (Ibidem); Savimbi, líder da UNITA (União Nacional para Independência Total de Angola), personagem "barbudo, de bengala, fardado" (Ibidem); Chipenda, líder militar, em constante trânsito por divergências, entre o MPLA (Movimento pela Libertação de Angola) e a FNLA, caracterizado como "bai-

5. Sobre a questão da presença de uma "pedagogia da esperança" (CAETANO, 2006, p. 46), consultese o ensaio de Marcelo Caetano (2006). 
xo e forte, garrafa à cinta" (Ibidem); e o racista, "sul-africano, branco, forte e com cara de mau" (Ibidem). Interessante observar neste grupo a presença marcante de traços que, a princípio, deveriam humanizar seus personagens, já que, no grupo seguinte (os 5 combatentes e o ator na platéia), o anonimato e a ausência de nomes e nacionalidades constitui uma marca definidora dos seus caracteres. Como dizíamos, aqueles traços definidores (nomes e nacionalidades) acabam por se tornar uma arma poderosa na construção dos nós da trama, já que cada um dos personagens - máscaras dramáticas dos líderes homônimos - passa por um processo de desumanização, no sentido de que o senso de pertença e identificação com o prêmio, a nação angolana, acaba sendo suplantado por interesses individuais que apagam os compromissos coletivos.

Não será gratuito, neste sentido, que ao longo da disputa do cabo de guerra, sobretudo quando o grupo dos revolucionários começa a ganhar vantagem e esboçar uma vitória fácil, o americano passe a planejar formas de contaminação do grupo oponente a partir de armadilhas bem elaboradas. A primeira é a do tribalismo, orquestrada por Savimbi, tendo como mote, não a união dos povos angolanos, mas a sua irremediável separação:

SAVIMBI: Dividir? Dividir é comigo. Eu divido tudo, o Povo, o País, as bananas, a mandioca, quatro a dividir por dois dá dois. Multiplicar ou somar já não sei, mas dividir... Aprendi na Suiça, quando tirei o curso de Doutor de seis meses (Ibidem, p. 23).

Ora, é sabido que Jonas Savimbi, o líder umbundo da UNITA, desentendeu-se com o MPLA por acreditar que o partido de Agostinho Neto favorecia não apenas os brancos, mas os cidadãos de etnia quimbunda, provocando uma total dependência com os estrangeiros (BIRMINGHAN, 2002) ${ }^{6}$. A fala do personagem homônimo na peça de Pepetela não deixa de ironizar agudamente esta postura, lançando mão de um processo de caricaturização, já que o título obtido aparece sob os auspícios de uma dubiedade beirando o cômico

6. Sobre tal desentendimento político, David Birminghan esclarece: "The leader of UNITA, Jonas Savimbi, revived his challenge to the regime by accusing it of being in the pocket of foreigners. $\mathrm{He}$ alleged that the MPLA government eas not only staffed by whites but was excessively parochial in its ethnic preference for Mbundu citizens" (2002, p. 151). 
("curso de Doutor de seis meses"), além de uma postura que o coloca em aliança direta com os mesmos estrangeiros, alvos de suas críticas ("Aprendi na Suiça"). Destarte, ironia e desconstrução mordaz passam a ser instrumentos eficazes na mão do autor, no momento de criação das personagens componentes do grupo dos imperialistas.

Se Savimbi aparece com tais tonalidades, as outras máscaras não perdem em termos de desmistificação. Assim, Holden aparece como uma espécie de títere, cuja única função é a de repetir aleatoriamente os discursos de outros sem conseguir emitir uma fala que indique o pensamento próprio e a consciência política, chegando mesmo a reproduzir um aparente apoio à política de segregacionismo racista, sem conseguir dar conta da real natureza dos temas levantados nos debates entre os seus comparsas de grupo ("HOLDEN: Racismo oyée!"; PEPETELA, 1978, p. 18). Ainda que apareça com uma veste evocadora da terra ("barrete de pele de leopardo"), não aparenta ter com seu espaço de origem qualquer laço de pertença, pelo contrário, as suas falas repetitivas só reiteram a sua condição de cegueira, indicada pelos óculos escuros, metáfora da sua visão embotada e deturpada. O efeito de repetição, assim, constitui-se um instrumento proposital, posto que não só deflagra um processo de desumanização do personagem, como também reitera a sua incapacidade de ver com os próprios olhos os anseios e necessidades da nação, a não ser os sentimentos escusos que movem os seus comparsas de grupo.

Chipenda, por sua vez, encarna o próprio descontrole político, além dos interesses pessoais sobre os da coletividade, fazendo coro com o discurso segregador do personagem Savimbi. Ao lado do divisionismo incontrolado deste e da cegueira de Holden, é a embriaguez uma de suas marcas desconstrutoras:

RACISTA: Cale a boca, não denuncies o nosso jogo.

CHIPENDA: (bebendo sempre pelo gargalo) Racistazinho, vem cá, meu amigo. Varremos agora o MPLA, depois o Savimbi e no fim o atrasado mental do Holden que não vê nada. Eu sou o Presidente e a Namíbia está lixada. E o Zimbabwé. E dou-te também o ferro de Cassinga e o urânio. Olha, todo o Sul de Angola fica uma nova Namíbia, queres?

RACISTA: Estúpido, estás bêbado. Já combinamos isso tudo, não é preciso falar mais (Ibidem, p. 19). 
$\mathrm{Na}$ verdade, o leitor depara-se com série de interesses pessoais elencados, corroborados, ora pela atitude manipuladora do personagem americano, ora pela violência e destemperança do personagem racista. Interessante observar que todos estes aspectos acabam por acarretar uma desumanização desses personagens, cuja atitude para abalar a força do grupo dos revolucionários não seria outra se não a de promover a desestabilização e a desunião. Com isto, para além de uma falta de sintonia destes personagens com os reais interesses da nação, eles também desvelam uma incompetência administrativa e política flagrantes, cujo auge seria a fuga e o abandono do cenário da disputa, quando percebida a vitória iminente dos revolucionários.

O segundo grupo traz em si uma característica comum que, a princípio, bem poderia ser entendida como um dado homogeneizador dos seus personagens, já que todos eles, ao serem interrogados por Likishi sobre seus nomes, respondem com um exclamativo: "Povo angolano!" (Ibidem, p. 12). Mas, aqui, aparece a consciência crítica do autor, no sentido de sublinhar que, por detrás desta aparente semelhança, há nítidas marcas de uma diferença, já que cada um destes representantes do povo angolano são partes constituintes de grupos étnicos distintos. $\mathrm{Na}$ caracterização dos componentes deste grupo de revolucionários, as indicações flagram tal exposição da multiplicidade étnica angolana, posto que os cinco combatentes aparecem, respectivamente, na seguinte ordem: "quimbundo, de Luanda" (Ibidem, p. 7), "Umbundo, do Huambo" (Ibidem), "Tchokuê, de Saurimo" (Ibidem), "Mestiço, de Cabinda" (Ibidem) e "Branco, do Lubango" (Ibidem).

Se, somente com a união de todos, desde os habitantes do litoral aos das áreas do interior territorial, juntamente com os representantes mestiço e branco, o Povo Angolano chegaria à vitória, a aposta de Pepetela parece realmente residir numa consciência das diferenças e na junção destas para a construção e consolidação dos caminhos independentes da Nação.

Mas, isto não resultaria numa visão meramente idealizada do contexto social, já que alguns deles são vítimas das armas utilizadas pelos membros do grupo dos imperialistas. Se, de um lado, Savimbi aparece como disseminador das desconfianças de "um feitiço, o tribalismo" (Ibidem, p. 42) contaminador, por outro, Chipenda entra em cena como semeador do "vírus do racismo" (Ibidem). Ou seja, diante de duas possíveis fragilidades, os combatentes po- 
deriam ver as suas tentativas de união minadas e a consolidação de um povo angolano marcado pela superação das distâncias étnicas comprometida. ${ }^{7}$

No entanto, é na confirmação não apenas de um ideal coletivo e nacional, mas de uma consciência político-partidária que os combatentes e Likishi fazem ecoar na última cena o leitmotiv do MPLA, logo após a vitória cabal sobre o grupo dos imperialistas: "Um só povo! Uma só nação!" (Ibidem, p. 49). Talvez, por causa disto, é que Iris Amâncio tenha afirmado não estranhar "o tom panfletário que habita toda a ação dramática e eclode no final” (2009, p. 249), referindo-se ao refrão entoado em uníssono pelos personagens vitoriosos. Mas, para além deste "tom panfletário", gosto de pensar, como Rita Desti, que $A$ corda constitui-se também "uma produção artística muito mais declaradamente que qualquer outra dirigida à criação duma consciência nacional” (1980, p. 92).

E como produção artística, como texto dramático, Pepetela vai buscar nas concepções brechtianas, por exemplo, uma maneira de atingir a sensibilidade identitária dos seus pares. Afinal, nesta construção aparentemente lúdica, não traz ele para dentro da urdidura da trama aquele "efeito de distanciação" (BRECHT, 2004, p. 474), qual seja, o de "fornecer ao espectador a possibilidade de exercer uma crítica fecunda, colocando-se do lado de fora da cena para que adquira um ponto de vista social" (Ibidem)? Não será proposital, neste sentido, a atuação de um personagem ator inserido no meio do público, respondendo aos apelos do dançarino Likishi, quando este solicita uma reação dos espectadores?

(Savimbi, Holden e Chipenda lutam por causa do dinheiro. O Americano olha para eles desgostoso, o sul-africano faz ginástica).

LIKISHI: Depois vão roubar-nos tudo, até a vida. Eu sou o árbitro, o juiz, não devo intervir. Mas dum lado há a pureza, embora com erros e defeitos. Do outro, só há a ganância, a vigarice. Eu, como Povo, devo ficar indiferente? Respondam, ajudem-me, devo ou não intervir?

(Espera a resposta do público. Um actor no meio do público, grita). ACTOR: Intervém!

7. Importante sublinhar que os dois temas não são desconhecidos no projeto literário de Pepetela. Basta lembrar, a título de exemplo, os conflitos tribais e étnicos entre os personagens guerrilheiros em Mayombe, romance escrito em 1971, ou seja, cinco anos antes da escrita de $A$ corda. 
LIKISHI: Vocês decidiram, vocês são o Povo. Eu só posso seguir as decisões do Povo. Por isso vos tenho pedido para pensarem. Quem manda é o povo, por isso o Povo deve pensar. Não é gritar só frases à toa, reagir por simpatia ou antipatia, mas sim fazer, sabendo o que se está a fazer. Vocês pensaram, vê-se que são um Povo maduro, ainda bem. (PEPETELA, 1978, p. 41-42).

Neste momento, o ato de pensar, de refletir, de desenvolver uma crítica madura sobre os principais acontecimentos que atingem o palco torna-se um gesto necessário não apenas àqueles que performatizam o jogo, mas também aos que presenciam a encenação, daí que o grito emitido pelo ator acaba por ganhar uma dimensão maior, de sentido coletivo, já que a sua voz representaria a necessidade coletiva de uma intervenção social do personagem dançarino, ferindo completamente as próprias regras lúdicas.

A interferência de Likishi acaba por amadurecer as paradas de auto-crítica e consolidar a capacidade dos combatentes em compreender os problemas causadores de uma fratura conflituosa e em superar as diferenças, respeitando-as a partir das suas percepções. Por este viés, gosto de pensar que a concepção deste personagem juiz encontra algumas consonâncias com o personagem "coringa", de Augusto Boal, sobretudo, no que diz respeito à sua polivalência cênica. Ao contrapor dois grandes grupos antagônicos e inserir um personagem apelante com uma função neutra no jogo e outro inserido no público e sensível ao apelo, Pepetela parece deshierarquizar a função de protagonismo na peça, já que, em cada cena, esta função passa a ser assumida por diferentes personagens. Se nas cenas I e X, sobretudo, a atuação de Likishi preenche a condição de protagonista na peça, em outras, tal função aparece desenhada nos movimentos dos combatentes (cenas III, VI, VII, IX e XII) e dos imperialistas (cenas IV, V, X e XI). Ainda assim, em todas as cenas, o dançarino não deixa de criar uma realidade mágica e "todos os personagens aceitam a realidade mágica criada e descrita” (BOAL, 1980a, p. 203) por ele. Tal criação, no entanto, não deve ser entendida como uma situação fora da realidade vivenciada pelos personagens, e sim como algo presente diante dos olhos de cada um deles, mas não perceptível, em virtude das artimanhas criadas para desviar a atenção dos personagens revolucionários. Daí que a intervenção de Likishi, para além de uma realidade criada por ele, estabelece um pacto de reflexão crítica com os combatentes e, por extensão, com os próprios leitores/espectadores: 
LIKISHI: Lutaram bem e agora vão perder, se não se puserem a pensar. Este combate não se ganha só com a força dos braços e com o sacrifício. Ganha-se com a cabeça.

3․ COMBATENTE: Nós usamos a cabeça, ó pai.

LIKISHI: Usam-na muito pouco, isso sim. Há bocado o Savimbi lançou-vos o seu feitiço, o tribalismo. À custa duma derrota, vocês aprenderam que era só um truque, um feitiço dos reacionários. Agora o Chipenda lançou-vos o vírus do racismo. Vocês não percebem que é o mesmo género de feitiçaria? $4^{\circ}$. COMBATENTE: Uns percebem, outros não.

LIKISHI: Os que percebem não são capazes de explicar aos outros? Então é porque não se sabem fazer entender e isso é grave. Têm medo agora que os brancos voltem a dominar, depois da vitória. Por isso, afastam o branco e o mulato, e perdem tudo. Se foram capazes de combater juntos, então, depois da vitória não serão capazes de vos organizar para impedir que uns explorem os outros? Se puderam combater juntos até agora, não poderão viver igualmente juntos, depois? (PEPETELA, 1978, p. 42-43).

Interessante observar que cada um dos personagens combatentes, ainda que individualizados pelos seus aspectos étnicos, utilizam sempre a primeira pessoa do plural nos diálogos estabelecidos entre eles, sobretudo, quando é necessário visualizar a apreensão de um determinado conteúdo ideológico e a sua compreensão coletiva, tal como pode ser observado na cena XI:

2․ COMBATENTE: É desta vez, é desta vez. Eles já não podem mais. $3^{\circ}$. COMBATENTE: Camaradas, pensaram já tudo? Aproveitar é agora. 1 . COMBATENTE: (para o quinto) Os brancos não vão querer-nos explorar depois?

5\%. COMBATENTE: Há diferenças entre brancos, como há entre os negros. Uns vão querer, outros vão até lutar contra esses que vão querer explorar.

$2^{\circ}$. COMBATENTE: Sim, é verdade. Temos de nos organizar para que depois não haja exploração. Já percebi, a exploração não tem cor. Depende de nós todos, da nossa capacidade de evitar que uns se aproveitem do trabalho dos outros. Sejam eles quem forem. Está certo! (Ibidem, p. 45; grifos meus). 
Diante de tais cenas, não seria possível pensar n' $A$ corda como uma espécie de "teatro-foro", como pensou Augusto Boal? Não são os discursos dos personagens revolucionários desenvolvidos de maneira significativa na "primeira pessoa do plural (mesmo que o tema seja proposto por um só indivíduo)" (BOAL, 1980a, p. 128)? As suas cenas não envolvem necessariamente "todos os participantes, os quais devem, todos, sentir-se igualmente oprimidos pela mesma opressão" (Ibidem)? Ora, assim sendo, ainda que não existam afirmações explícitas de contato do autor com o criador do teatro do oprimido, não é possível perceber ressonâncias deste nas malhas do drama pepeteliano?

Vale lembrar que a poética dramática de Pepetela constitui-se também, na sua essência, uma expressão artística que não se pretende desvinculada da preocupação político-social. Neste sentido, encontra diálogo com as propostas do teatro do oprimido de Augusto Boal, posto que, para o dramaturgo brasileiro, "todo teatro é necessariamente político, porque políticas são todas as atividades do homem, e o teatro é uma delas" (1980b, p. 1). Dando espaço a vozes oprimidas por forças limitadoras das mais diversas ordens (internas e externas), não deixa Pepetela de recorrer aos recursos cênicos, caros à prática estética de Boal, por exemplo, sem perder de vista os recursos possíveis e disponíveis para a sua atividade criadora.

Uma das marcas mais significativas desta preocupação ética aliada a uma realização estética bem acabada encontra-se na articulação cênica do personagem Likishi. Juiz, dançarino e artista, toda a sua performance não exclui as manifestações culturais de sua terra, sobretudo, a música, com o ngoma e os chocalhos:

O som de ngoma aumenta e torna-se frenético.

Entram por cada lado do palco dois grupos de cinco pessoas, uns fazendo piruetas, outros marchando, como na apresentação dum circo. Cada um dos grupos alinha ao lado do Likishi, ficando este no meio. Diminui o som do ngoma e o Likishi fala.

LIKISHI: Estão aqui as duas equipas, prontas para um combate que a África nunca viu. Cada uma das equipas puxará a corda e quem conseguir levar o lenço até a tabuleta 3 do seu lado será o vencedor. Simples, não é? Mas é nas coisas simples que se encontram os verdadeiros problemas. (Dança, sempre ao som do ngoma e chocalho). Mas, atenção! Este combate tem regras. Sempre que 
uma tabuleta seja alcançada pelo lenço, haverá descanso. (Ri, dançando). É, para durar mais tempo, para vocês poderem pensar. Não esqueçam de pensar. (Dança). Para quê este combate? Apenas uma brincadeira de crianças? Eu vou explicar. $\mathrm{O}$ vencedor ficará com Angola. O país, as suas riquezas, vocês todos, nós todos, pertenceremos ao vencedor. Percebem agora porque é importante este combate?

(Dança, batendo nos ombros de cada adversário). (PEPETELA, 1978, p. 9).

Mais do que um intermediador entre as duas forças em questão, Likishi apela para a atitude reflexiva de seus participantes. Sua performance envolve não apenas o ato de uma interrogação constante sobre o combate encenado, mas uma ação movida por sons e músicas que evocam as mais profundas tradições angolanas. Neste sentido, gosto de pensar que, realmente, o papel deste personagem pode ser o de coringa, posto que cria uma realidade mágica, trazendo uma corda e apresentando os dois grupos dispostos a partir desta, mas não poderia ser ele também uma espécie de reflexo especular de seu próprio criador? Não estaria Pepetela, de cena a cena - da mesma forma como Likishi motivando o pensar dos combatentes -, incitando uma reflexão de seus leitores/espectadores? Não seria possível entender, no apelo acima citado de Likishi aos jovens combatentes angolanos, um eco da exortação exposta logo na cena I, dirigida ao leitor/público ("LIKISHI: Abram os olhos, abram os ouvidos, deixem de respirar. A vossa vida está em jogo, a nossa vida depende deste combate. Quem irá ganhar?"; Ibidem, p. 8, grifos meus)? Quem, na verdade, estaria performatizando a fala inicial e convidativa (e para quem: grupo dos revolucionários no palco ou plateia?) a um exercício do pensar, criatura ou criador?

Levando em conta a modificação pronominal operada na fala do dançarino (de "vossa" para "nossa" vida), não estaria também este pretenso personagem neutro se incluindo no gesto de pensar e de intervir na sua realidade criada a partir de uma corda, de um simples mas complexo jogo de crianças? Ora, se o teatro de Pepetela preenche aquela configuração de um teatro "posto ao serviço de uma verdadeira pedagogia social" (BRECHT In: BORIE et alii, 2004, p. 466), bem ao gosto da pena brechtiana, não se pode cair na armadilha de acreditar que se trata de um texto puramente pensado numa dimensão panfletária, pelo contrário, a presença da música, de um persona- 
gem dançarino, de grupos e forças antagônicas me levam a crer que o teatro de Pepetela constitui-se também uma prática bem acabada de uma estética dramática, que cumpre a sua função político-social, sem perder de vista a elaboração estético-textual.

Neste sentido é que Pepetela, de certa forma, frustra salutarmente aqueles que procuram n' $A$ corda apenas uma motivação ética para sua criação, quando, na verdade, esta aparece de forma atrelada a uma prática estética. Assim fundindo estas duas forças, não deixa o autor angolano de se inserir naquela linhagem do teatro atual, conforme sublinhado por Jean-Pierre Ryngaert: "A criação contemporânea e a escrita moderna se inscrevem já de início neste teatro da ruptura, da renovação e da interrogação” (1998, p. 39).

Desta forma, estabelecendo uma ruptura com a comodidade, renovando a cena literária angolana e estimulando a interrogação, Pepetela traça diálogos dramáticos com as ideias brechtianas e boalianas, construindo com oprimidos e revolucionários uma corda utópica, resistente e mobilizadora. Afinal, não é este o propósito da própria criação literária? Assim sendo, são com estes nós que o autor angolano amarra $A$ corda e com ela dá aos seus leitores uma Angola possível.

\section{Referências bibliográficas}

ABRANTES, José Mena. O teatro em Angola. Luanda: Nzila, 2004, V. 1.

ALMEIDA, Lilian Pestre de. O teatro negro de Aimé Césaire. Niterói: UFF/CEUFF, 1978.

AMÂNCIO, Iris Maria da Costa. A corda: um convite ao pensar. In: CHAVES, Rita \& MACÊDO, Tania (org.). Portanto... Pepetela. São Paulo: Ateliê Editorial, 2009, p. 249-254.

BIRMINGHAN, David. Angola. In: CHABAL, Patrick (org.). A History Postcolonial Lusophone Africa. London: Hurst \& Company, 2002, p. 137-184.

BOAL, Augusto. Stop: c'est magique! Rio de Janeiro: Civilização Brasileira, 1980a.

Teatro do oprimido e outras poéticas políticas. 2. ed. Rio de Janeiro: Civilização Brasileira, 1980b.

BRANCO, João. Dez anos de teatro. Mindelo: Centro Cultural Português/Instituto Camões, 2003.

. Nação teatro. História do teatro em Cabo Verde. Mindelo: Instituto da Biblioteca Nacional e do Disco, 2004. 
BRECHT, Bertold. Escritos sobre o teatro. In: BORIE, Monique et alii. Estética teatral: textos de Platão a Brecht. 2. ed. Trad.: Helena Barbas. Lisboa: Fundação Calouste Gulbenkian, 2004, p. 465-491.

CAETANO, Cristina Maia. Conhecer o teatro em Moçambique. Pinhel: Pinhel, 2004.

CAETANO, Marcelo. A pedagogia da esperança em As aventuras de Ngunga. In: Scripta. Revista do Programa de Pós-Graduação em Letras e do Centro de Estudos Lusoafro-brasileiros da PUC-Minas. v. 10, no. 19, Belo Horizonte: PUC-Minas, 2006, p. 43-53.

CARNEIRO, João. Recensão crítica a $A$ revolta da casa dos idolos, de Pepetela. In: Colóquio/Letras 70. Lisboa: Fundação Calouste Gulbenkian, novembro de 1982, p. 97-98.

DESTI, Rita. Recensão crítica a A corda, de Pepetela. Colóquio/Letras 54. Lisboa: Fundação Calouste Gulbenkian, março de 1980, p. 91-92.

HILDEBRANDO, Antonio. A revolta da casa dos idolos: a nação em cena. Dissertação de mestrado em Literatura Comparada. Universidade Federal Fluminense, Niterói, 1996.

- A revolta da casa dos ídolos: renovação e tradição. In: CHAVES, Rita \& MACÊED, Tania (org.). Portanto... Pepetela. São Paulo: Ateliê Editorial, 2009, p. 255259.

REBELLO, Luiz Francisco. Recensão crítica a No velho ninguém toca, de Costa Andrade. In: Colóquio/Letras 59. Lisboa: Fundação Calouste Gulbenkian, janeiro de 1981, p. 84-85.

RYNGAERT, Jean-Pierre. Ler o teatro contemporâneo. Trad.: Andréa Stahel M. da Silva. São Paulo: Martins Fontes, 1990.

VAZ, Carlos. Para um conhecimento do teatro africano. Lisboa: Ulmeiro, 1999.

Recebido em 25 de junho e aprovado em 13 de outubro de 2012. 